\title{
Objectivity, Historicity, Taxonomy
}

\author{
Joeri Witteveen ${ }^{1,2,3}$ (D)
}

Received: 14 June 2016/ Accepted: 1 April 2017/Published online: 20 April 2017

(C) The Author(s) 2017. This article is an open access publication

\begin{abstract}
In Objectivity (2007), Daston and Galison argue that scientific objectivity has a history. Objectivity emerged as a distinct nineteenth-century "epistemic virtue," flanked in time by other epistemic virtues. The authors trace the origins of scientific objectivity by identifying changes in images from scientific atlases from different periods, but they emphasize that the same history could be narrated using different sorts of scientific objects. One could, for example, focus on the changing uses of "type specimens" in biological taxonomy. Daston (Crit Inq 31(1):153-182, 2004) indeed provides a detailed account of the history of the type specimen which purports to show this. I argue that this attempt hinges on a conceptual confusion and therefore fails. I show that the actual history of the type specimen does not reinforce the account of epistemic virtues from Objectivity, but rather threatens to subvert it.
\end{abstract}

\section{Introduction}

"Scientific objectivity has a history." This is the thesis that historians of science Lorraine Daston and Peter Galison (henceforth: D\&G) have developed and defended in several articles (Daston 1992, 1998, 1999a, b, 2001; Daston and Galison 1992; Galison 1998, 1999), which have culminated in the monumental book Objectivity (Daston and Galison 2007). In this corpus of scholarly work D\&G argue that the very idea of epistemic objectivity in science emerged as late as the midnineteenth century. Objectivity was a novel "epistemic virtue" — a particular ethical

Joeri Witteveen

j.witteveen@uu.nl

1 Descartes Centre for the History and Philosophy of the Sciences and the Humanities, Utrecht University, Utrecht, The Netherlands

2 Department of Philosophy and Religious Studies, Utrecht University, Utrecht, The Netherlands

3 Department of Psychology, Utrecht University, Utrecht, The Netherlands 
imperative concerning the acquisition, presentation, and justification of scientific knowledge.

D\&G's research on scientific objectivity is an exercise in historical epistemology, which they understand as the study of how new epistemological categories, problems, and concepts crystallize out of changing practices for gaining and justifying knowledge (Daston 2009; Galison 2008). This approach has a quasiKantian flavor to it. It studies the preconditions that make a new concept possible, while understanding those preconditions in terms of historical, contextual practices (Daston 1994; Feest and Sturm 2011). In adopting this approach, D\&G reject the idea that epistemic concepts have a timeless and monolithic nature that can be studied by means of conceptual analysis. They view the method of conceptual analysis with suspicion, finding it an "unpromising tool for understanding what objectivity is, much less how it came to be what it is" (Daston and Galison 2007, p. 52). Unlike received philosophical analyses of objectivity, their historicalepistemological approach does not help itself to clean-cut, decontexualized distinctions between varieties of objectivity - metaphysical, methodological, epistemic, moral-but allows for the possibility that our thinking about objectivity bears the marks of its contingent history. "If the concept grew historically, by gradual accretion and extension from practices, it is not so surprising that its structure is confused rather than crystalline" (ibid., p. 52-53).

Unsurprisingly, D\&G's historical-epistemological study of scientific objectivity has raised questions among philosophers. ${ }^{1}$ For example, Sturm (2011) wonders how the study of scientific practices as such is supposed to improve our understanding of scientific objectivity. Surely, practices themselves do not dictate what counts as objective scientific knowledge; the epistemic ideals that govern them do. Why, then, don't D\&G focus on the philosophical arguments and debates that led scientists to accept certain ideals and reject others? Kusch (2009) on the other hand has suggested that D\&G's practice-based approach could be refined philosophically by taking cues from Wittgenstein. Kusch points out that there are interesting parallels between D\&G's approach and Wittgenstein's account of how entrenched social practices can generate new epistemic certainties, categories, and concepts through a process of decontextualization (Wittgenstein 1969). Finally, Ian Hacking-himself a prominate advocate of historical epistemology-has suggested that the contrast between D\&G's approach and 'standard' conceptual analysis is in fact less marked than they assert (Hacking in Dear et al. 2012, p. 31).

This paper aims to contribute to the critical philosophical discussion of D\&G's historical epistemology of objectivity, but does so from an importantly different angle. Instead of weighing the merits and shortcomings of D\&G's project by comparing and contrasting it with received philosophical approaches, I will assess the internal consistency of their account. More specifically, I will examine whether D\&G's framework for interpreting the practices they associate with scientific objectivity succeeds by their own standards. I will argue that it does not, for reasons that return us to philosophy: D\&G's framework misrepresents important parts of the

\footnotetext{
${ }^{1}$ For a general philosophical discussion of historical epistemology, see the special issue of Erkenntnis edited by Feest and Sturm (2011).
} 
history it aims to capture because it fails to draw important philosophical distinctions.

The entrypoint for my discussion is an observation $D \& G$ make about the practices one could potentially study to discern the emergence of scientific objectivity. In their own work, D\&G focus almost exclusively on the practice of making scientific atlases: compendia of images that teach scientists about the defining objects of inquiry of their discipline. In a close study of several dozens of atlases from a wide range of sciences-from botany to crystallography, from anatomy to meteorology - they chart developments in the methods and aims of representing nature from the mid-eighteenth century onwards. However, D\&G also emphasize that atlas images are not the only expressions of the epistemic virtues they are concerned with (e.g. Daston and Galison 2007, p. 27). Their project is not a history of scientific atlases per se; they are merely using atlas images to track changes in epistemic virtues: "For our purposes, scientific atlases are an index, not the primary subject matter" (Daston and Galison 2008, p. 667). In principle the history of objectivity could be narrated using any other kind of vehicle of scientific knowledge-any other kind of "working object":

Working objects can be atlas images, type specimens, or laboratory processes - any manageable, communal representative of the sector of nature under investigation. No science can do without such standardized working objects, for unrefined natural objects are too quirkily particular to cooperate in generalizations and comparisons.

Daston and Galison (2007, p. 19)

In some of their writings $D \& G$ take up one of these alternative working objects: type specimens - specimens that have been serving a central but changing role in the practice of biological taxonomy (Daston 2004; Daston and Galison 2007, pp. 105-112). D\&G's history of the type specimen serves to testify that their account of epistemic virtues is independent of the working object studied.

I will argue that this attempt is unsuccesful. I will show that, instead of reinforcing the account of epistemic virtues from Objectivity, the history of the type specimen threatens to subvert it. D\&G fail to see this, because their understanding of the history of the type specimen hinges on a conceptual confusion. They confound issues about representation with issues about reference. A philosophical error has distorted their historiography.

The remainder of this article is structured as follows. The next section sketches the contours of D\&G's account of changing epistemic virtues on the basis of their histories of atlas-making (Sect. 2.1) and type specimens (Sect. 2.2). In Sect. 3, I then show that D\&G's account of type specimens rests on conceptual confusion between representation and reference. In Sects. 4 and 5, I articulate this distinction in the context of biological taxonomy and show that it results in an understanding of objectivity that does not sit well with D\&G's account. Finally, in Sect. 6, I discuss the repercussions for D\&G's overall account of what objectivity is and how it came to be. 


\section{Working Objects and Epistemic Virtues}

\subsection{Atlas Images and Epistemic Virtues}

D\&G's account of epistemic virtues in their book Objectivity commences with a study of late-Enlightenment atlas images. The pages of scientific atlases from this period were filled with highly stylized and idealized images that demonstrate the scientists' aim to extract nature's hidden universals from a series of aggregated sense impressions. The guiding ideal of the truth-to-nature scientist was the depiction of nature's underlying essences, stripped of the surface variation that occludes them from us in every single encounter. Putting this ideal into practice was the privilege of scientific savants who-often in close collaboration with artistssynthesized the universals on the basis of their intimate and life-long experience with a domain of nature.

Within the domain of truth-to-nature depiction, D\&G draw a further distinction between ideal images and characteristic images. Ideal images aimed at representing hidden universals by synthesizing them from a series of individually distorted surface manifestations. Examples of this kind of imagery are depictions of Johann Wolfgang von Goethe's Urpflanze and Carolus Linnaeus's images of species and genera. Characteristic images, in contrast, aimed at precisely depicting a typical exemplar of a class under investigation. D\&G count images of both kinds as truthto-nature imagery, since both were governed by a regulative ideal of willful interpretation and idealization.

In the course of the nineteenth century, D\&G tell us, many scientists came to regard truth-to-nature atlases as suspect. They got concerned about their own tendency to idealize and perfect observations so as to fit pre-conceived expectations and hypotheses. The mid-nineteenth century thus saw the emergence of a new conception of the "scientific self" as overly interpretive and dangerously subjective. To suppress these vicious tendencies of their own personalities, scientists asserted the duty to discipline themselves. A new ideal of the scientist emerged as someone who followed strict procedures and relied on mechanical tools to register nature without intervention. For only by disciplining themselves in this way could scientists be expected to capture nature objectively, with all its particularities. Thus was born the epistemic virtue of (mechanical) objectivity.

When we reach the early-twentieth century, D\&G argue that atlas images begin to mirror the ascent of yet another epistemic virtue. Advocates of the virtue of trained judgment complained that the regulative ideal of objectivity had been a pipe dream, and attempts to silence the interpretive voice of the atlas-maker had been a mistake. Trained judgment reintroduced an active role for the scientist, but without sliding back into truth-to-nature representation. It removed the polar opposition between objectivity and subjectivity by positioning the scientist neither as a willabnegating worker nor as an isolated sage who interprets nature at his own discretion, but rather as someone who learns to discern patterns in nature through extensive training, embedded in a tightly connected scientific community. The atlas images of trained judgment still relied on mechanically produced representations, 
but these now began to serve as unprocessed signposts that required further interpretation. Atlas images became proxies for coordinated efforts of pattern detection.

\subsection{Type Specimens and Epistemic Virtues}

As I mentioned in the introduction, D\&G claim that their periodization of epistemic virtues can also be articulated and illuminated by turning to the history of type specimens-specimens that have served a central but changing role in the history of taxonomy.

Daston's (2004) account of this history begins with the observation that lateeighteenth and early-nineteenth-century naturalists used the word "type" in two different senses that correspond closely to the distinction between ideal and characteristic images. Some naturalists used "type" to refer to an essential form underlying a spectrum of variation in a certain group of organisms. The quest for types in this sense was akin to the quest for the representational targets of ideal images. As in Objectivity, Daston mentions Linnaeus and Goethe in this context. "They concurred that their task was to extract the truths of nature from the welter of confusing appearances... Theirs was a truth of synthetic perception, of the ability to detect a common form uniting many individual exemplars of a kind" (Daston 2004, pp. 166-167).

The second use of "type" corresponds to the input of a characteristic image: the most characteristic or typical member of a group. This is the notion of types Daston is primarily interested in, because it formed the basis for the earliest conception of a 'type specimen.' The English polymath William Whewell offered a lapidary definition of this notion of types in late-eighteenth and early-nineteenth-century natural history:

A Type is an example of any class, for instance, a species of a genus, which is considered as eminently possessing the characters of the class ... The Typespecies of every genus, the Type-genus of every family, is, then, one which possesses all the characters and properties of the genus in a marked and prominent manner.

Whewell (1847, Vol I; pp. 494-495); cited in Daston (2004, p. 170)

This Whewellian notion of a type was part and parcel of what Whewell referred to as the "Method of Type." A type could be used as a proxy for describing a taxon ${ }^{2}$, or as a means to refine knowledge of taxon boundaries. By comparing types with other elements of the same rank, taxonomists determined which elements belonged to which taxa.

Daston argues that this Whewellian type concept and the associated Method of Type were evidently rooted in a truth-to-nature epistemology: "An individual specimen could serve as a type, but only on the basis of a careful selection on the basis of a thorough acquaintance with the species it was intended to exemplify, in

\footnotetext{
${ }^{2}$ A taxon (plural: taxa) is a taxonomic group of some rank. At the species-rank one finds species taxa (i.e. individual species), at the genus-rank genus taxa (i.e. individual genera), and so on for higher ranks.
} 
turn the basis of the naturalist's synthetic judgment of the distinguishing marks of the species" (ibid., p. 171). Interestingly, however, Daston notes that this same notion of types paved the way for a later break with the truth-to-nature virtue and for a transition towards objectivity. This happened when Whewellian types were no longer merely used as proxies for describing and delimiting biological taxa, but in addition got mobilized to address a pressing issue in taxonomic nomenclature. Taxonomists began to use types to help combat the problem of synonymy: the state of one taxon being known to different taxonomists by different names.

To see the relevance of Whewellian types for combatting synonymy, we first need to get clear on what the problem of synonymy in taxonomy amounts to. Synonymy, Daston explains, can be a severe threat to effective communication between taxonomists. By the early nineteenth century, the increasing decentralization of taxonomy was causing different naturalists to pin different names on the same taxa. The "cacophony of names" (ibid., p. 171) this resulted in could easily create misunderstandings and was likely to cause taxonomists to talk past each other. Among the naturalists who worried most about these developments was the British geologist and ornithologist Hugh Edwin Strickland, who launched an initiative to stamp out synonymy and bring taxonomists' use of names in tune again. Under the auspices of the British Association for the Advancement of Science (BAAS), Strickland set up a commission charged with the formulation of an authoritative set of nomenclatural rules that any self-respecting zoologist would have to live by.

The most important tenet of these "Strickland Rules," as they soon became known, was its formalization of the "principle of priority." This principle stated that the only real name of a taxon is the first name given to it. The Strickland Rules and its principle of priority set the standard for similar nomenclatural rules that were being drafted for other domains of natural history, such as botany and entomology. However, Daston notes, some naturalists realized that the principle of priority on its own could not call the proliferation of synonyms to a halt. Additional measures needed to be taken. As Daston puts it: "Some [further] standard was needed to transfer authority from persons to nature and glue names permanently and unambiguously to things" (ibid., p. 174). This is where Whewellian types re-enter the story. In the course of the nineteenth century, these types were co-opted as standards for the application of taxon names. Proposals were adopted to permanently anchor the valid name of each taxon to the type that belonged to that taxon. From then on, one could determine the only valid name of a taxon by consulting its type. In disputes about names, types had the last word.

As I mentioned earlier, Daston claims that these developments signalled a departure from the epistemic virtue of truth-to-nature-we can now begin to understand why. The departure is reflected in the changed meaning of the term "type" that resulted from the co-option of Whewellian types as fixed anchors for taxon names. The result was that "type" no longer referred to a typical specimen, but instead began to denote the first specimen collected by a naturalist who named a new species. And since such a first specimen could turn out to be a rather aberrant member of its species in the light of further sampling, this had the bizarre 
consequence that "the type of the species was typically no longer typical" (ibid., p. 174).

This post-Whewellian use of types as fixed name-bearers became known as the "type method." Though similar in name to Whewell's own "Method of Type" we have just seen that it constituted a somewhat puzzling departure from that method, and thereby from the truth-to-nature virtue. Nonetheless, Daston argues that the rationale of this departure was clear: the new type method promised to solve the problem of synonymy by making the naming of taxa a truly objective affair. On the new type method, the job of ascertaining the type of a species was no longer the prerogative of a sage who could be trusted to isolate the typical from the accidental. Instead, a species' type could now be selected and identified by anyone who complied with the "mechanical application" of nomenclatural rules that codified the type method (ibid., p. 176). The new type method therefore "came to be seen as a triumph of objectivity in taxonomy" (Daston and Galison 2007, p. 111).

In correspondence with D\&G's account of atlas images, Daston's account of types includes a further transition from objectivity to trained judgment. Daston argues that the advent of this transition was signalled by the dissatisfied response of some taxonomists to the new, objective method of mitigating synonymy. While welcoming the nomenclatural benefits of the new type method, these taxonomists objected to the considerable cost at which it was bought. For now that type specimens weren't typically typical any longer, they had become defective devices for representing the distinguishing features of their species. The type method had effectively transformed type specimens into unrepresentative representatives of their species (Daston 2004, p. 179). Daston sums up the new situation as one in which "taxonomists once more had a common language, albeit one purchased at the price of paradox, an atypical type" (ibid., p. 163).

From a conceptual point of view, this enigmatic notion of a type specimen presented a serious roadblock to taxonomic practice. But in practice, Daston argues, taxonomists learned not to be disturbed by the paradox. Rather than attempting to dis(solve) the paradox, they simply worked around it. They effectively neutralized the problem of unrepresentative representation by adjusting their practices of classification. Instead of strongly leaning on type specimens as reliable bases of comparison, they began to use type specimens dynamically and in combination with knowledge of other specimens and species descriptions to gradually discern the connections between conspecifics. Daston notes that it is hard to capture this complex practice in simple terms, but she illustrates it as the making of "a wheel of comparisons, each a point along the hub representing an individual specimen connected along a spoke to the type specimen at the center, as well as connected to one another by relationships of resemblance." (ibid., p. 181;) In any case, it is clear that in Daston's view this new practice marked the advent of new epistemic virtue, for she notes that "it is the trained eye and judgment of the botanist that discerns these connections, shuttling back and forth among holotype ${ }^{3}$, description, and other specimens" (ibid., p. 181; italics added). In short, the problems of unrepresentative

\footnotetext{
3 "Holotype" is another term for a name-bearing type specimen that was selected at the time of naming a (sub)species.
} 
representation that had been introduced by the type method were offset by doing taxonomy differently, in the spirit of trained judgment.

Let me briefly recap this voyage of the type specimen through three epistemic virtues, as presented by Daston (2004). First, there was the truth-to-nature type specimen of the late-eighteenth and early-nineteeth-century Method of Type: an exemplary specimen that was used to delineate and describe a species, and that had been selected on the basis of a learned naturalist's deeply personal experience with nature. Then, with the introduction of the type method in the course of the nineteenth century, type specimens gained an additional role as objective, fixed name-bearers of species names. Taxonomic codes of nomenclature began to specify that for each new species, the name-giver of that species had to designate a type specimen to which the species name would be anchored once and for all. This elaboration of the role of type specimens came at a cost: it implied that a type specimen was typically no longer typical of its species and therefore could no longer adequately represent its species' distinguishing features. Type specimens had been turned into unrepresentative representatives. At a conceptual level this paradox remains with us today, but in practice taxonomists have learned to live with it. By embracing the twentieth-century epistemic virtue of trained judgment taxonomists have managed to dovetail in a practical manner what are, conceptually speaking, two principally irreconcilable functions of type specimens.

\section{The Paradox that Never was}

The previous section has shown that Daston's (2004) account of the history of the type specimen is in tune with the general framework of epistemic virtues from Objectivity. It supports D\&G's claim that their historical-epistemological account of objectivity applies to other kinds of working objects than atlas images. In addition, Daston's account reinforces their view that philosophical analysis is an unpromising tool for understanding what objectivity is or how it came to be. If Daston is right, the notion of a type specimen that has been hammered out over the past two centuries remains philosophically enigmatic — a "seemingly impossible hybrid" from a conceptual viewpoint (ibid., p. 164).

The way out of this philosophical dead-end, Daston has shown, is to realize that the taxonomists who invented the type method "were primarily concerned with practices, not philosophy" (ibid., p. 157). She accordingly labels her approach of coming to grips with the history of the type specimen one of "applied metaphysics" or "metaphysics in action" (ibid., pp. 158, 182) —an historiographical approach that focuses on how practices can bring objects and concepts into being as well as remove them from scientific inquiry (Daston 2000).

Daston's detailed attention to taxonomic practices is important. It would be hard to appreciate the complex history of the type specimen without such a focus. However, I will argue that Daston is mistaken in claiming that tracing practices is important because philosophy can't help us make sense of the notion of a type specimen. On the contrary, I will argue that we need philosophical input to make sense of the history of the type specimen. I will demonstrate that, ironically, 
Daston's decision to brush conceptual analysis aside leads her to miss a conceptual distinction that is crucial for understanding the history of the type specimen: the distinction between reference and representation. Daston tends to jumble these two notions; she gradually collapses her discussion of reference into that of representation. Because of this, she ends up concluding that the history of the type specimen involved a conceptual paradox. I will argue that this paradox is a mirage; it is an artifact of Daston's error. In the next section, I will show that when we properly distinguish between matters of reference and matters of representation the history of the type specimen begins to look importantly different from how Daston presented it.

\section{Revisiting the History of the Type Specimen}

To gain a firm understanding of the problem that the type method would eventually provide a solution for, we need to return to Linnaean times. A major part of Linnaeus's taxonomic efforts was to publish revisions of hypotheses about the boundaries of higher taxa-genera, families, etc.-in the light of new taxonomic materials, methodologies, and theories of classification. Yet, necessary as these revisions were, Linnaeus realized that they introduced problems for the naming of biological taxa. When future taxonomists, with more taxonomic material at their disposal, would come to judge that a certain Linnaean genus was in fact a composite of two or more smaller genera, this could easily lead to nomenclatural confusion. Inevitably, taxonomists would sometimes differ in their judgments about what part of a split genus should count as the original genus minus the separated part(s). These differences in interpretation would in turn cause them to use the original genus name for different genera after a revision. Rampant miscommunication would ensue. $^{4}$

To forestall this confusion, Linnaeus made a proposal. He suggested that whenever a genus was to be split into two or more genera, the original genus name should be kept to denote that new genus that was most typical of the original genus (Linnaeus 1736, §246). Linnaeus’s proposal caught on. Many late-eighteenth and early-nineteenth-century taxonomists rehearsed the Linnaean dictum in their monographs and followed it in practice. When Hugh Strickland (see Sect. 2.2, p. 5) became interested in issues of taxonomic nomenclature in the 1830s, he similarly recapitulated that: "Where an old genus is divided into several new ones, new appellations must, of course, be found for them; but, even then, the original name should be retained for that group which is the most typical of the whole" (Strickland 1835 , p. 39). As Strickland put it in later publication, in any revision of a genus its name ought to follow "the type of the genus" in the sense codified by Whewell (Strickland 1838, p. 331).

The above shows that from Linnaean times until at least the early-nineteenth century, the correct assignment of taxon names hinged on the correct identification of the typical element of a taxon. Taxonomic names hitchhiked on whatever an

\footnotetext{
$\overline{{ }^{4} \text { For a more detailed account of this history, see Witteveen (2016). }}$
} 
expert taxonomist judged to be the taxon's typical element. What to do, though, if two experts disagreed in their judgments of typicality?

This became a live question in the early-nineteenth-century context of a rapidly expanding and decentralizing taxonomic enterprise. With an increasing number of taxonomists making independent taxonomic judgments, disputes began to emerge about what was the most typical member of a taxon. The ornithologist Charles Thorold Wood noted, for example, that "it frequently happens, that naturalists cannot agree on the type of the family: thus, Selby pronounces the genus Sílvia to be the type of its family; Swainson says, on the other hand, Régulus; and Blyth, rejecting both, adopts Ficédula as the typical genus ... and so on throughout zoology" (Wood 1836, p. 340). An even more pressing problem was raised by entomologist John Obadiah Westwood. He pointed out that even if taxonomists could agree about what the typical member of a group is at a given time, the continued discovery of new specimens (and groups) over time entails that "the supposed typical group will be continually subject to variation" (Westwood 1828 , p. 4). Westwood concluded that he did "not know any method so likely to create confusion and uncertainty as that contained in this [Linnaean] rule" (ibid., p. 5). The crux of the problem was that the inevitable capriciousness in judgments about the representation of a genus' features directly impacted the determination of the referent of a genus' name. The way forward would be to cleave matters of reference from disputes about representation.

Accordingly, Westwood suggested an alternative approach for deciding which part of a split genus should "inherit" the original genus name. He proposed a new rule: taxonomists would have to permanently anchor a genus name to that part of the genus which had been considered typical by the original name-giver. This entailed that taxonomists should stop relying on their individual, fickle taxonomic judgments to determine the referent of an original genus name after a splitting event. All they would have to do, was to find out which species the name-giver of the original genus had judged to be its type species (Westwood 1837).

Westwood's proposal was the first explicit formulation of what would later become known as the "type method." Soon enough, it was incorporated into the Strickland Rules, which stated unambiguously that "when a genus is subdivided into other genera, the original name should be retained for that portion of it which exhibits in the greatest degree its essential characters as at first defined. Authors frequently indicate this by selecting some one species as a fixed point of reference, which they term the 'type of the genus'" (Strickland 1843, p. 110; italics in original). Note how Strickland here uses the same phrase- "the type of the genus" - as 5 years earlier, but with a completely different meaning. Strickland no longer understood a taxon's type to be that taxon's typical component as judged by any competent taxonomist, but rather as the typical component as judged by the discoverer and name-giver of that taxon. This latter component, Strickland now suggested, would have to be used as the permanent anchor for the taxon's name.

Importantly, a name-bearing type in this sense could unproblematically serve its purpose even when no living taxonomist considered it to be typical of its taxon. Name-bearing types did not need to be typical, since they did not serve any role in the practice of describing or delimiting taxa. For that purpose, taxonomists could 
continue to rely on the Whewellian practice of identifying typical elements in the light of the latest taxonomic knowledge. The only purpose name-bearing types served, was that of helping taxonomists determine the rightful name of a taxon in the light of their latest classification. The types of the type method provided fixed anchors for names amidst the high seas of classificatory changes.

As word of the Strickland Rules spread, the type method was gradually incorporated into other codes of nomenclature that were being formulated for domains other than zoology. Interestingly, however, all of these nineteenth-century codes of nomenclature-the Strickland code included-only discussed the use of reference-fixing type species and/or type genera; they did not mention type specimens. Only by the early-twentieth century did some codes begin to incorporate articles that spoke of "The nomenclatorial type of a species or subspecies...the specimen to which the describer originally applied the name in publication" (Arthur et al. 1904, Sect. 14). The exact reasons for this "delay" in the application of the type method to species names need not concern us here (but see Witteveen (2016) for details). In any case, in the wider taxonomic literature the notion of a namebearing type specimen had already been making the rounds since the earlynineteenth century. In 1819, the Swiss botanist Augustin-Pyramus de Candolle already pointed out that the "types originaux," the specimens that "served as the type for the descriptions of original authors," needed to be preserved at all costs because of "the fixity they give to nomenclature" (Candolle 1819, p. 321; my translation).

The implementation of the type method for species names also meant that another old Linnaean practice had to be abandoned. In Linnaean times, it had been common practice to discard those specimens on the basis of which a species had been named whenever more typical conspecific specimens could be acquired for one's collection. This practice hinged on the experienced naturalist's ability to determine whether or not two specimens belonged to the same species. But as we have already seen in the case of higher taxa, the inevitable subjectivity of such judgments could create problems down the line. What one taxonomist once judged to be two conspecific gatherings, a later taxonomist might judge to be gatherings of different species. The only way to adjudicate on such disputes was to never dispose of the original specimens on the basis of which a species name had been introduced, regardless of how atypical those specimens might be.

Let me sum up this brief history of taxonomic naming and reference. Up to the early-nineteenth century, the terms "type specimen," "type species," and "type genus" were used to denote taxon members that were judged to be typical of their encompassing taxa. In the course of the nineteenth century, these terms gained a second, distinct meaning. They were co-opted to denote taxon members of a different kind: fixed name-bearing elements. The practice of assigning fixed namebearing elements, the type method, solved the problem of establishing the correct name for a revised taxonomic hypothesis. For example, determining the name of a species became a matter of consulting the type specimen that fell within the species' boundaries and reading the species name off the label attached to it. The one and only role name-bearing specimens served was to establish a definite link between a name and a species. The wording of codes of nomenclature have always made it 
very clear that they used the term "type specimen" in this purely name-bearing sense. Indeed, codes of nomenclature continue to emphasize to this day that "the device of name-bearing types allows names to be applied to taxa without infringing upon taxonomic judgment" (Ride et al. 1999, preamble).

\section{Fixing Reference}

The brief revisionist historiography from the previous section demonstrates that when issues about taxonomic naming and reference are placed in the foreground, the history of the type specimen ends up looking rather different from how it was presented by Daston (2004). Most crucially, it reveals that the novel nineteenth century notion of a type specimen was not paradoxical at all. This notion of a type specimen did not refer to an amalgam of two principally irreconcilable functions, but signalled the use of a familiar term for a new kind of specimen.

This is not to deny that the historical decision to co-opt the term "type" for these specimens has been rather confusing. Among non-taxonomists "type" is bound to evoke suggestions of typical representation where none are implied. ${ }^{5}$ Professional taxonomists have indeed been duly aware that non-experts are liable to "confuse the type of a name with the typification or other representation of the group named" (Simpson 1961, p. 31). This confusion appears to be exactly what led Daston to characterize the modern notion of a type specimen as an "impossible hybrid": a conceptually inscrutable fusion of a representative species-exemplar and a potentially unrepresentative name-bearer (Daston 2004, p. 165). The impossibility disappears when we realize that the hybridity never was. The type specimens of the type method are name-bearers pur sang. They only fix the reference of the taxon name they are labelled with. Determining the sense of a taxon name calls for taxonomic hypothesizing, which is something a fixed name-bearer cannot help with.

This final point, about the distinction between reference and sense (Frege 1892), provides a bridge to a more philosophical discussion of taxonomic naming. It can be used to flesh out the idea that the type method ties in with an influential philosophical account of reference: the causal theory of reference (Kripke 1972; Putnam 1975). The causal theory of reference has two central tenets. The first is that the referent of a proper name or a kind term is fixed in by means of a baptismal act. The second is that subsequent uses of that name are linked to the baptism by way of reference-preserving chains of communication. This is to say that names succeed in referring to the same entity by virtue of standing in a causal chain that originated with the initial baptism, and not by virtue of the description later users associate with that name. The causal theory thus supports the idea that names are rigid designators: they inhere rigidly in their referents in spite of users having different conceptions of those referents. This appears to be exactly to how taxonomic names

\footnotetext{
5 Several twentieth-century taxonomists indeed attempted purge the term "name-bearing type" from the taxonomists' vocabulary by introducing alternatives such as "onomatophore" (Simpson 1940) or "nomenifer" (Schopf 1960). Yet none of these alternatives have caught on. The terminology of "types," "nomenclatural types," and "name-bearing types" remains deeply entrenched in the taxonomist's vocabulary.
} 
function when they are anchored to species by means of type specimens. A taxonomic name thereby comes to rigidly designate its referent while allowing for taxonomists to have different conceptions of that referent. ${ }^{6}$

Interestingly, Daston considers the possibility that a causal-theoretical picture might account for taxonomic naming on the type method. However, she ends up rejecting this option because of several "striking disanalogies ... between the aims of rigid designators in the theory of reference and those of type specimens in nomenclature" (Daston 2004, p. 178). In the remainder of this section I will argue that all of her objections derive from misunderstandings of either the type method or the causal theory. The first purported disanalogy Daston mentions, is that

in contrast to rigid designators, botanical type specimens are not independent of the truth of the description of the species they instantiate. ... [I]f a species description clearly disagrees with the type specimen, the description trumps, and names are applied accordingly.

Daston (ibid., p. 178)

This is incorrect; a species description cannot "trump" a type specimen. Since the type method defines "type specimen" as "the name-bearer for the species it belongs to," a type specimen for a certain species name cannot fail to belong to the species it names, no matter how flawed the accompanying description may turn out to be. ${ }^{7}$ In other words, a type specimen necessarily belongs to the species it names (Hull 1982; Witteveen 2015; Ereshefsky 2007).

The second disanalogy Daston draws attention to, involves the widely held metaphysical view that species are large-scale individuals rather than sets, classes, or kinds. She argues that this raises a concern for the causal-theoretical interpretation of taxon names:

If type specimens are just parts of the species-individual that can be pointed out to define the (from the standpoint of human perception) scattered speciesindividual, why insist upon the singularity of the holotype ${ }^{8}$ Why aren't more parts better than one, as they surely would be if one were trying to reconstruct an organism from, for example, fragmentary and dispersed fossil remains?

Daston (2004, p. 178)

Daston's question illustrates her confusion about the difference between sense and reference. The reason one part is better than several is simple: modern-day type specimens do not help to define or reconstruct species, but only serve to fix the

\footnotetext{
6 A more elaborate account of taxonomic names as rigid designators requires an excursion into possible worlds. I do not have the space to discuss this background here, but for detailed treatments see Haber (2012), Witteveen (2015).

7 Daston cites a particular article of a particular code of nomenclature in support of her point: Article 7.4 of the The International Code of Botanical Nomenclature (Greuter et al. 2000). Apart from the question this raises about the generality of her claim-does it also apply to zoology? - the claim itself is not supported by the article she cites. I will not dwell on the technicalities and jargon of Article 7.4 here, but will convey its main message: a name counts as erroneous when it is used for a taxon that fails to include the name's nomenclatural type. Put simply: types trump descriptions. This is a straightforward implication of the type method and the opposite of Daston's claim.

${ }^{8}$ See footnote 3 .
} 
reference of species names. For the later purpose a singular specimen is obviously preferable: fixing a species name using two or more name-bearing specimens already involves the fallible taxonomic judgment that both specimens belong to the same species.

Finally, Daston argues that even pinning a name to a single specimen may already introduce a disanalogy with the causal theory. After all, on the causal theory

the relationship between rigid designator and the natural kind it names is bipartite; there is no equivalent of the unique, individual type specimen to mediate between name and thing. There is, to continue with the example of water, no designated brook or sea that serves as the sole type specimen of that natural kind.

Daston (ibid., p. 179)

The causal theorist will disagree with Daston on there being a "bipartite" relationship between name and kind. To stay with the example of "water": Putnam famously argued that we could imagine that its referent had been fixed by someone who pointed at a lake and uttered the word "water" (Putnam 1975). His point was that the reference of "water" must have been fixed through contact with part of its extension. Determining the full extension of "water" required researchers to get their hands wet and determine what stands in the relevant sameness relation to the baptized sample. To claim that the namer of "water" had immediate bipartite contact with all of water is to misunderstand the very point of the causal theory: a reference can be fixed in a baptism, whereas determining its sense and/or extension calls for empirical work. ${ }^{9}$ The same holds for species; their names can be fixed by assigning type specimens for each putative new species, but establishing species boundaries requires empirical taxonomic work.

If these replies to Daston (2004) are along the right lines, they put pressure on her suggestion that philosophical theory has little to offer for understanding the history of the type specimen. On the contrary, I have aimed to show that a proper understanding of the distinction between sense and reference can help us gain a more solid understanding of relevant nineteenth-century developments.

\section{The Disunity of Objectivity}

In the introduction of this article I drew attention to D\&G's (2007) claim that not just atlas images, but any common object of scientific inquiry-any 'working object' - could be used to narrate the history of objectivity. We have since seen how Daston (2004) attempted to do this using type specimens. We have also seen that her account is problematic because it hinges on a conceptual confusion. In this final section I will explore the implications for D\&G's broader claims about what objectivity is and how it came to be.

\footnotetext{
9 An important relevant difference — not discussed by Daston-between a type specimen and the sample for "water" is that the former is an example of an archived and curated sample-an actual record of the baptism. If anything, the absence of archived samples for natural kind terms like "water" should decrease our confidence that the causal theory applies to them (cf. Mellor 1977; Chang 2012).
} 
For a start, we can note that D\&G's general account of two transitions between three epistemic virtues is not supported by the historiography of the type specimen. Section 4 has revealed that the history of taxonomic reference systems does not involve different uses of a single kind of working object in relation to different epistemic virtues. The problem, we have seen, is that D\&G's taxonomy of epistemic virtues is tied to a dynamic of changing regimes of representation, whereas the history of the type specimen is about how issues of representation were cleaved from matters of reference. In other words, the history of the type specimen involves an extra dimension that falls outside the scope of D\&G's framework.

This problem becomes particularly vivid when we look at the purported transition from truth-to-nature to mechanical objectivity. In their writings on atlas images, D\&G tell us that this transition was constituted by scientists' increasing dissatisfaction with the highly individualistic judgment of truth-to-nature representation. But in the history of the type specimen we find no signs of an equivalent sentiment. None of the early promoters of the type method argued that the representation of species ought to be mechanical or automatic. Instead, they took issue with the entwinement of truth-to-nature representation and the assignment of taxon names. They objected to the use of personal taxonomic judgment as a basis for the assignment of names in a taxonomic revision.

D\&G might reply by granting this point while denying that it poses much of a problem for their overall framework of epistemic virtues. They might respond that the category of objectivity is wider than that of mechanical objectivity about representation and that it also encompasses a variety of "referential objectivity" the kind of objectivity we encounter in the history of the type specimen. In fact, $D \& G$ have already responded along these lines to other critics, who raised concerns about the epistemic virtue of "structural objectivity" (e.g. in Dear et al. 2012).

In Objectivity, D\&G introduce the epistemic virtue of structural objectivity as a side-branch to their otherwise linear account of transitions from truth-to-nature to mechanical objectivity and trained judgment. They tell us that the adherents of structural objectivity departed from mechanical objectivity in regarding all scientific imagery as suspect tout court. Only "structures"-abstract, often logical relations that go beyond personal experience-could be objectively communicated between scientists. ${ }^{10}$ This has led critics to ask what the relation is between mechanical and structural objectivity. Why, if these two varieties are opposed to each other, should we count both as aspects of scientific objectivity? $D \& G$ respond:

On our account, scientific objectivity always counters some aspect of the self, but not always the same one. This is why the genus objectivity embraces the species of both mechanical and structural objectivity and no doubt potentially others as well. Because the subjectivity is multifarious, objectivity must be too.

D\&G in Dear (2012, p. 31)

\footnotetext{
${ }^{10}$ Among the proponents of structural objectivity were philosophers such as Frege, Carnap, Poincaré, and Russell. See Daston and Galison (2007, Chap. 5).
} 
This response is not entirely satisfactory, since it fails to answer how we should characterize the "generic scientific self" that constitutes the glue to the virtue of scientific objectivity. We have seen that the scientific self of mechanical objectivity was a willful, and (over)interpreting self that needed to be reined in by exercise of self-restraint through strict, mechanical procedures. The self of structural objectivity, we learn from D\&G, was a "claustral, private self menaced by solipsism" (Daston and Galison 2007, p. 257) for whom the individuality of experience was so suspect that only the most abstract, formalized representations of all could be shared objectively. The scientific self of referential objectivity could maybe be characterized as someone who feared Babylonian speech confusion, and in response became a watchman of the word, a strict rule-follower about reference. ${ }^{11}$ What is the common denominator among these personae that makes them aspects of a single overarching scientific self?

If we limit ourselves to mechanical and structural objectivity, it seems clear that they are united in attempting to curb a scientific self that imposes its own interpretation on the presentation of data. Mechanical and structural objectivity could even be considered different magnitudes of essentially the same response. D\&G indeed suggest at some point that "structural objectivity was, in some senses, an intensification of mechanical objectivity, more royalist than the king" (ibid., p. 259). But, even if one accepts this line of $\operatorname{argument}^{12}$, it no longer works straightforwardly when we bring referential objectivity into the mix, since the proponents of referential objectivity embraced the subjectivity of representation instead of fighting it. They could live happily with the fact that individualistic, interpretive taxonomic judgment was required to be a good taxonomist. Their aim was not to curb the interpreting self, but rather to facilitate communication of subjective taxonomic judgments.

This point about referential objectivity being in harmony rather than in opposition to the subjectivity of representation can be developed a little further by looking directly at the relation between referential and mechanical objectivity. The nature of this relation is illustrated nicely by the reaction of the late-nineteenthcentury paleontologist Francis Bather to the new practice of representing species by mechanically amalgamating images of individual specimens. (It is worth noting that this method, which Bather characterized as the "method of composite portraiture, as developed by Mr. Francis Galton and others" (p. 5) is presented as a hallmark of mechanical objectivity by D\&G. See Daston and Galison (ibid., p. 169ff.).) Bather did not object to this approach per se, but he did object to those who claimed that it obviated the need for name-bearing types. He warned that one taxonomist's

\footnotetext{
11 Alternatively, one could argue that referential objectivity is part of the broader category of communitarian objectivity - a notion of objectivity that Daston discussed at length in several early essays on objectivity (Daston 1999a, b, 2001), but which is strikingly absent from Objectivity. I will ignore this further complication here.

12 Several commentators have not. They find it hard to see how D\&G's explanation of the unity of objectivity in terms of a complementary scientific self could ever be genuinely explanatory (e.g. Kusch 2009, 2011; Dear et al. 2012). I am inclined to agree, but my aim here is to show that D\&G run into trouble even we remain neutral, for the moment, on the possibility that their account of explanation might work.
} 
selection of specimens for a composite "species portrait" risked creating what in the eyes of another taxonomist would be "a cement of fiction ... [by] artfully combin[ing] individual belonging to two different species. Well may the systematist despair" (Bather 1893, p. 5). Thus, Bather concluded, since any attempt at representation is subjective and fallible, the designation of type specimens as fixed and objective anchors for names "must be held to be the prime necessity" (ibid., p. 5). ${ }^{13}$ Bather's line of reasoning underscores that referential objectivity is not aimed at inhibiting or constraining the subjectivity of the self, but is instead aimed at making subjectivity communicable.

We can conclude, then, that D\&G's account of what constitutes the generic virtue of scientific objectivity needs further development at the very least. D\&G's framework does not tell us why mechanical, structural, and referential objectivity all count as species of objectivity, because it does not provide us with a substantive account of a unitary scientific self to which all and only varieties of objectivity are a response. Moreover, we have seen that it might be hard to construct such an account. If, as I have argued, the varieties of objectivity cross-cut each other in fundamental ways, it seems that the scientific selves they are wedded to are similarly disunified. That, in turn, would mean that D\&G's project of accounting for the unity in objectivity would run into trouble.

What is the alternative? This is not the place to offer a worked-out account of objectivity and its history that avoids the pitfalls I identified in D\&G's account, but I suggest that it would be promising to work from the ground upwards, by looking for causal explanations of the emergence of objectivity of various kinds and in various domains, without presupposing that these converge on a meaningful relation to a coherent scientific self. In Objectivity, D\&G make clear that for them this is not an option: explanations in terms of local causes "obscure rather than clarify" what objectivity is and how it came to be (p. 36). Causal explanations are too local, too specific, to catch the kind of wide-ranging patterns they are looking for. Yet, as adamant as $D \& G$ are in rejecting causal explanations, they have unwittingly shown their potential. In fact, we encountered a lead for a causal history of objectivity in Daston's (2004) history of the type specimen. We encountered a lead for a causal history of objectivity. For, in spite of its flaws, Daston's account was correct in pointing to the expansion and decentralization of early-nineteenth-century taxonomy as the drivers of confusion about names to which objectivity was the solution. In this essay, I have picked up on this lead and used it to sketch one small strand of a historically- and philosophically-informed history of objectivity.

Acknowledgements I would like to thank two reviewers for this journal and audiences at Utrecht University and Tilburg University for valuable comments and criticism.

Open Access This article is distributed under the terms of the Creative Commons Attribution 4.0 International License (http://creativecommons.org/licenses/by/4.0/), which permits unrestricted use, distribution, and reproduction in any medium, provided you give appropriate credit to the original

\footnotetext{
13 The same lesson still forms the heart of the International Code of Zoological Nomenclature, whose first edition already stated: "Nucleus of a taxon and foundation of its name, the type is objective and does not change, whereas the limits of the species are subjectivity and liable to change" (Stoll et al. 1961, Art. 61).
} 
author(s) and the source, provide a link to the Creative Commons license, and indicate if changes were made.

\section{References}

Arthur, J. C., et al. (1904). Code of botanical nomenclature. Bulletin of the Torrey Botanical Club, 31(5), 249-261.

Bather, F. A. (1893). Crinoidea of Gotland. Part 1: The Crinoidea Inadunata (p. 18). Stockholm: Norstedt. de Candolle, A.-P. (1819). Théorie élémentaire de la Botanique (Seconde ed.). Paris: Déterville.

Chang, H. (2012). Is water H2O?: Evidence, pluralism and realism. Dordrecht: Springer.

Daston, L. (1992). Objectivity and the escape from perspective. Social Studies of Science, 22(4), 597-618.

Daston, L. (1994). Historical epistemology. In J. Chandler, A. I. Davidson, \& H. Harootunian (Eds.), Questions of evidence: Proof, practice, and persuasion across the disciplines (pp. 282-289). Chicago: University of Chicago Press.

Daston, L. (1998). Fear \& loathing of the imagination in science. Daedalus, 127(1), 73-95.

Daston, L. (1999a). Objectivity versus truth. In H. E. Büdeker, P. H. Beill, \& J. Schlumbohm (Eds.), Wissenschaft als kulturelle Praxis 1750-1900 (pp. 17-32). Göttingen: Vandenhoeck \& Ruprecht.

Daston, L. (1999b). The moralized objectivities of nineteenth-century science. In W. Carl \& L. Daston (Eds.), Wahrheit und Geschichte (pp. 78-100). Göttingen: Vandenhoeck \& Ruprecht.

Daston, L. (2000). The coming into being of scientific objects. In L. Daston (Ed.), Biographies of scientific objects (pp. 1-14). Chicago, IL: University of Chicago Press.

Daston, L. (2001). Scientific objectivity with and without words. In P. Becker \& W. Clark (Eds.), Little tools of knowledge historical essays on academic and bureaucratic practices (pp. 259-284). Ann Arbor: University of Michigan Press.

Daston, L. (2004). Type specimens and scientific memory. Critical Inquiry, 31(1), 153-182.

Daston, L. (2009). Comments on schickore and sturm: Where do epistemological problems come from? In Sturm, T., and Feest, U. (Eds.), What (Good) is Historical Epistemology? Max Planck Institute for the History of Science (pp. 35-37), Preprint 386.

Daston, L., \& Galison, P. (1992). The image of objectivity. Representations, 40, 81-128.

Daston, L., \& Galison, P. (2007). Objectivity. New York: Zone Books.

Daston, L., \& Galison, P. (2008). Response: Objectivity and its critics. Victorian Studies, 50(4), 666-677.

Dear, P., Hacking, I., Jones, M. L., Daston, L., \& Galison, P. (2012). Book symposium: Objectivity in historical perspective. Metascience, 21(1), 11-39.

Ereshefsky, M. (2007). Foundational issues concerning taxa and taxon names. Systematic Biology, 56(2), 295-301.

Feest, U., \& Sturm, T. (2011). What (good) is historical epistemology? Editors' introduction. Erkenntnis, 75(3), 285-302.

Frege, G. (1892). Über sinn und bedeutung. Zeitschrift für Philosophie und philosophische Kritik, 100, 25-50.

Galison, P. (1998). Judgment after objectivity. In C. A. Jones \& P. Galison (Eds.), Picturing science, producing art (pp. 327-359). New York: Routledge.

Galison, P. (1999). Objectivity is romantic. In Friedman, J., Galison, P., and Haack, S. (Eds.), The humanities and the sciences (pp. 15-43). Washington D.C.: ACLS Occasional Paper, no. 47.

Galison, P. (2008). Ten problems in history and philosophy of science. Isis, 99(1), 111-124.

Greuter, W., et al. (2000). International Code of Botanical Nomenclature (St. Louis Code). Königstein: Koeltz Scientific Books.

Haber, M. H. (2012). How to misidentify a type specimen. Biology and Philosophy, 27(6), 767-784.

Hull, D. L. (1982). Exemplars and scientific change. PSA: Proceedings of the Biennial meeting of the philosophy of science association pp. 479-503.

Kripke, S. A. (1972). Naming and necessity. Oxford: Blackwell.

Kusch, M. (2009). Genealogy, metrology, historical epistemology. In Presentation at the historical epistemology conference, Leuven, December 10-12.

Kusch, M. (2011). Reflexivity, relativism, microhistory: Three desiderata for historical epistemologies. Erkenntnis, 75(3), 483-494. 
Linnaeus, C. (1736). Fundamenta botanica. Amstelodami: Salomonem Schouten.

Mellor, D. H. (1977). Natural kinds. The British Journal for the Philosophy of Science, 28(4), $299-312$.

Putnam, H. (1975). The meaning of 'meaning'. In Gunderson, K. (Ed.), Language, mind and knowledge. (Minnesota Studies in the Philosophy of Science, Vol. VII) (pp. 131-193). Minneapolis: University of Minnesota Press.

Ride, W., Cogger, H., Dupuis, C., Kraus, O., Mineli, A., \& Thompson, C. (Eds). (1999). International code of zoological nomenclature, 4th edn. International Trust for Zoological Nomenclature.

Schopf, J. M. (1960). Emphasis on holotype (?). Science, 131(3406), 1043.

Simpson, G. G. (1940). Types in modern taxonomy. American Journal of Science, 238(6), 413-431.

Simpson, G. G. (1961). Principles of animal taxonomy. New York: Columbia University Press.

Stoll, N. et al. (Eds). (1961). International code of zoological nomenclature, 1st edn. London: International Trust for Zoological Nomenclature.

Strickland, H. E. (1835). On the arbitrary alteration of established terms in natural history. Magazine of Natural History, 8, 36-40.

Strickland, H. E. (1838). Remarks on Mr. Ogilby's 'Further observations on rules for nomenclature'. Magazine of Natural History, 2, 198-204.

Strickland, H. E. (1843). Report of a committee appointed to consider of the rules by which the nomenclature of zoology may be established on a uniform and permanent basis. Report of the twelfth meeting of the British association for the advancement of science, pp. 105-129.

Sturm, T. (2011). Historical epistemology or history of epistemology? The case of the relation between perception and judgment. Erkenntnis, 75(3), 303-324.

Westwood, J. O. (1828). On the Chalcididae. Zoological Journal, 4, 3-31.

Westwood, J. O. (1837). On generic nomenclature. Magazine of Natural History, 1, 169-173.

Whewell, W. (1847). The philosophy of the inductive sciences: Founded upon their history (2 Vols) (Vol. 1). London: John W Parker.

Witteveen, J. (2015). Naming and contingency: The type method of biological taxonomy. Biology \& Philosophy, 30, 569-580.

Witteveen, J. (2016). Suppressing synonymy with a homonym: The emergence of the nomenclatural type concept in nineteenth century natural history. Journal of the History of Biology, 49(135-189).

Wittgenstein, L. (1969). On certainty. Oxford: Blackwell.

Wood, C. T. (1836). Remarks on the question of the propriety of altering established scientific names in natural history, should they be erroneous. Magazine of Natural History, 9(63), 337-342. 